\title{
Picturing the Family: Media, Narrative, Memory
}

\section{Edited by Silke Arnold-de Simine and Joanne Leal}

\section{London and New York: Bloomsbury, 2018}

ISBN 978-1-4712-8360-1

\section{Reviewed by Annebella Pollen, University of Brighton, UK}

With origins in a 2014 conference at Birkbeck, University of London, Picturing the Family comprises ten essays mostly exploring family photography, although family representations on film are also included. Nine of the twelve authors are British and, distinctively, five are practising artists. Also notable is the gender make-up of the collection; only one male author features. As the subtitle of the volume suggests, stories and memories, and the consequent complexities that these areas open out, are core themes. As such, the contributions utilise and apply pre-existing work in the area, including Roland Barthes, Marianne Hirsch, Annette Kuhn, Elizabeth Edwards and, not least, Martha Langford.

It is fitting, then, that Langford opens the volume with an English-language translation of an essay previously published in French. Always insightful, she describes how mothers (and images of mothers) become "human flagpoles" (p. 20) on which cultural expectations are hung. Langford reconsiders the decisions she and her political scientist brother made when producing their book about their father's Cold War tourism in the early 1960s. Looking again at the photographs of their mother that they excluded, Langford now reads her "appeals to the camera" as an act akin to "a vast sisterhood of posing women" (p. 23), many anonymous, who can be found across the corpus of vernacular photography. Langford weaves this wife and a mother into a complex geopolitical context, taking in the Cuban missile crisis, the fashioned appearance of Jackie Kennedy and Canadian civil defence strategy. She considers the "indecisive moments" in which her mother is caught as a means to question photographic certainties, and reveals how the studied poses can conceal local and international dramas.

Lizzie Thynne's chapter is less resolved but takes a similar theme in that it reflects back on a previous work by the author - in this case, an artist's film - which explored her mother's life and photographs. Thynne analyses her own production alongside two other films made by female artists about their mothers, specifically those of Alina Marazzi and Mariana Otero. Together these works show that the complexity of family stories are not unified and closed by the act of filmic mediation. Oksana Sarkisova and Olga Shevchenko's chapter, on Soviet Heroes and Jewish Victims, discusses how divergent modes 
are at play in the conflicting narratives constructed around family photographs. They examine one particular example from their wider study on post-Soviet family photographic archives. Like Langford's, this exploration shows the productive results of reading family photography in relation to larger cultural, political and national narratives. In this approach, both "the banal" and "the historical", and their lacunae, can be read against one another.

Artist Suze Adams asks a pertinent question in her chapter about the broader significance of working with family photography: "Is this only a daughter's nostalgic longing for her mother or is it a tale that will reach out to others [...]?" Arguably, there are as many tales as there are families, and the complexities of photographs to tell overlapping narratives of people, places, times and technologies, not to mention history and memory, means that the outer limits of such discussions are hard to see. This is not to suggest that the stories not worth telling but contributors carry a burden to frame their particular tales in ways that extend the contexts, research methods and interpretive methodology of family photography as a field of study, and not simply to add new case studies. Arts practice offers the potential to do things differently, although this book does not capture its products especially well. Adams, for example, deliberates at length about the meanings of her family photograph album from Mull, Scotland, but the end result of her reinterpretation of the material appears to be photographic reprints arranged on a humble pinboard and a detailed family tree reproduced at a scale too small to be unreadable. Thynne's film is represented by stills that fail to capture its depth or dynamism. In part these are shortcomings of the book's production; an academic format including only small monochrome illustrations doesn't do artwork justice, but in many cases crucial information such as dimensions and materials are missing from the captions, meaning that art is hard to grasp.

Sally Waterman's filmic works suffer a similar fate. The importance she applies to soundtrack and choreography is discussed but can't be seen. Waterman quotes Geoffrey Batchen on photographs and memory. "Something must be done to the photograph", he argued, "to pull it (and us) out of the past and into the present" (2004: 94). That "something" motivates art interventions but it isn't always delivered in this volume. Many of the studies provide an autoethnographic perspective on artists' mothers, grandmothers and daughters. This provides structural coherence but also some repetition. In many cases the deeply personal nature of the subject matter operates as a means of healing wounds or coming to terms with grief. These are important emotional processes and they sometimes take place over very long periods (see, for example, Jacqueline Butler's chapter, where she discusses her photographic exploration of female relationships in her family over a 20 year period). Deborah Schultz's 
chapter on Chino Otsuka's witty photographic manipulation of her childhood photographs provides a different perspective on how artistic engagement can enhance meaning. "Projects like Otusoka's", Schultz notes, "are not only about the figures represented but are equally about the nature of the images created through the photographic medium" (p. 148). This is an important point of extrapolation: it is the connection that personal narratives make to wider frames of reference and the broader information that they provide about photography as a form that constitutes the value of such a study. Some contributions to this volume remain too introspective for their broader value to be seen.

Richard Lowell MacDonald addresses the move from private photograph to public discourse in his chapter, "A Place for Memory: Family Photo Collections, Social Media and the Imaginative Reconstruction of the Working-Class Neighbourhood". His study of the Salford Past online community challenges the "scopic restlessness" that Daniel Rubenstein and Katrina Sluis have identified as the mode by which digitally-networked photographs are mostly apprehended. In the forum MacDonald scrutinises, photographed are engaged with over time, at length and in opposition to the nostalgia and romanticisation that one might expect. MacDonald sees this as a particular classed form of identity; those who reflect on memories of Salford Past also reflect on the danger of their manual work and the disappointments of constrained social mobility.

Nicky Bird, another artist contributor, instead of working on her own family, reflects critically on those who work with found photographs, acting in some cases as "custodians", watching over the material, "keeping it from the dustbin and oblivion" (p. 175). Bird trawls eBay for photographs that have not been bid upon and gathers not only the unwanted photographs but also the narratives applied to them by their sellers. Through these manoeuvres, she carefully considers the multiplicity of authorships in the creation of photographic meaning, including her own and those of the collectors who buy her artworks. Processes of de- and re-contextualisation are also the topic of Silke Arnold-de Simine's final chapter. Here she explores the challenge that remains when the Holocaust is publicly acknowledged as a historical fact, but the individual involvements of families in its practices are still privately denied. Photographs play a particular role in this, Arnold-de Simine argues, not least in Beate Niemann's memoir, which revealed the truth of her father's Nazi past behind the photographs in which he performed loving a parental role. Again, this is a daughter's work.

Arnold-de Simine also usefully challenges the warm and fuzzy glow that can result from the "familial gaze", that is, the afiliatory emotions prompted by looking at a stranger's family photographs. She speaks of what this gaze cannot do: it "does not help us understand the integral violence of a racist 
politics of belonging in which the logic of kinship can condemn you to death" (p. 207). Empathy might, instead, be characterised as sentimental and parochial; she argues that "interrogation of our own investments" is required (p. 208). Picturing the Family takes up this challenge; the results can be rich but overall the volume is uneven in its handling of its material. This is perhaps testament to the nature of form. Family photographs are open-ended, never neatly resolved and often opaque. They bridge private and public, are entangled in hearts and minds, and complicate selves and others. 